Review

\title{
Reprogramming into pancreatic endocrine cells based on developmental cues
}

\author{
Simon Kordowich ${ }^{\mathrm{a}}$, Ahmed Mansouri ${ }^{\mathrm{a}, \mathrm{c}}$, Patrick Collombat ${ }^{\mathrm{a}, \mathrm{b}, \mathrm{c}, \mathrm{d}, *}$ \\ a Max-Planck Institute for Biophysical Chemistry, Department of Molecular Cell Biology, Am Fassberg, D-37077 Göttingen, Germany \\ ${ }^{\mathrm{b}}$ Inserm U636, Mouse Molecular Genetics Department, FR-06108 Nice, France \\ ${ }^{\mathrm{c}}$ Beta Cell Biology Consortium, 2213 Garland Avenue, 9465 MRB IV, Nashville, TN 37323-0494, USA \\ d Juvenile Diabetes Research Foundation, 120 Wall Street, New York, NY 10005, USA
}

\section{A R T I C L E I N F O}

\section{Article history:}

Received 14 April 2009

Received in revised form

14 September 2009

Accepted 24 October 2009

\section{Keywords:}

Endocrine pancreas development

Arx

Pax4

Mouse

Diabetes

Fate specification

\begin{abstract}
A B S T R A C T
Due to the increasing prevalence of type 1 diabetes and the complications arising from actual therapies, alternative treatments need to be established. In order to compensate the beta-cell deficiency associated with type 1 diabetes, current research focuses on new strategies to generate insulin-producing beta-cells for transplantation purpose, including the differentiation of stem or progenitor cells, as well as the transdifferentiation of dispensable mature cell types. However, to successfully force specific cells to adopt a functional beta-cell fate or phenotype, a better understanding of the molecular mechanisms underlying beta-cell genesis is required. The present short review summarizes the hitherto known functions and interplays of several key factors involved in the development of the different endocrine cell lineages during pancreas morphogenesis, as well as their potential to direct the generation of beta-cells. Furthermore, an emphasis is made on beta-cell regeneration and the determinants implicated.
\end{abstract}

(c) 2009 Elsevier Ireland Ltd. All rights reserved.

\section{Contents}

1. Introduction.

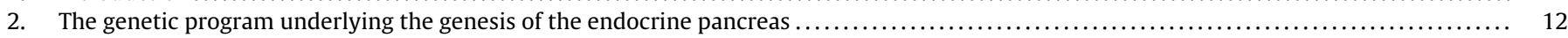

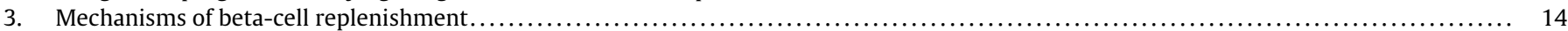

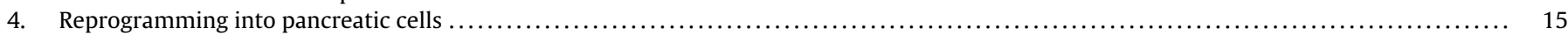

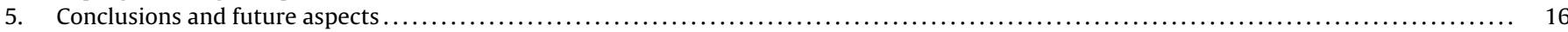

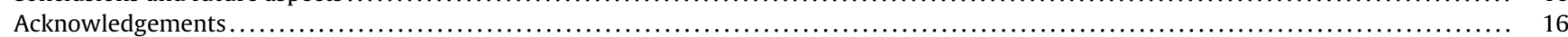

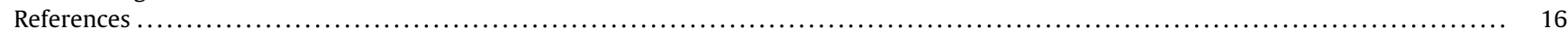

\section{Introduction}

Over the past decades, diabetes has become one of the most widespread metabolic disorders with epidemic dimension affecting almost $6 \%$ of the world's population. By the year 2025, the number of people affected by type 1 or 2 diabetes is projected to reach 300 million. For instance, in Asia, where a fast change in lifestyle and dietary habits is occurring, the number of diabetic patients is increasing faster than anywhere else. Herein, we will focus on type 1 diabetes, which is characterized by a selective loss of insulin-producing beta-cells in the endocrine pancreas as a result of an autoimmune reaction. Left untreated, the induced shortage

\footnotetext{
* Corresponding author at: Inserm U636, Diabetes Genetic Team, FR-06108 Nice, France.

E-mail address: collombat@unice.fr (P. Collombat).
}

in insulin hormone and resulting hyperglycemic condition may lead to complications, such as micro- and macro-vascular damage, blindness, amputation and/or death. Current treatments involve daily injections of exogenous insulin in order to compensate the deficiency in this hormone. However, environmental factors, such as exercise, diet, or age, may cause marked variations in blood glucose levels despite insulin therapy and eventually lead to the complications discussed previously. Islet transplantation represents a substitute to insulin therapy, but the shortage in donors prevents its widespread use. Thus, other alternatives must be found in order to efficiently treat the consequences of type 1 , but also type 2 , diabetes, both diseases eventually resulting in loss and/or insufficient numbers of beta-cells.

In this context, the generation of pancreatic beta-cells from stem, progenitor or other cell subtypes may represent an interesting option. However, to design rational protocols allowing the 
in vitro or in vivo generation of beta-cells, it is imperative to gain further insight into the molecular determinants controlling the development of embryonic, but also adult beta-cells, in vivo.

\section{The genetic program underlying the genesis of the endocrine pancreas}

The pancreas plays a crucial role in nutritional homeostasis through synthesis and secretion of hormones and enzymes. This organ includes three tissue-types: acinar, ductal and endocrine. The exocrine pancreas consists of acinar cells secreting digestive enzymes, such as amylases, lipases, proteases and nucleases, which are emptied into the pancreatic duct forming an elaborately branched network of tubules, composed of epithelial cells. Acinar cells also produce bicarbonate ions and electrolytes, which together with exocrine enzymes, are transported through the main duct into the duodenum, where they contribute to food processing (Githens et al., 1994). Endocrine cells are organized into small clusters of cells termed islets of Langerhans. These correspond to specialized micro-organs composed of five original cell subtypes, including alpha-, beta-, delta-, epsilon-, and PP-cells, which produce the hormones glucagon, insulin, somatostatin, ghrelin, and PP (Pancreatic Polypeptide), respectively. Insulin and glucagon function coordinately to control glucose homeostasis, whereas somatostatin and PP regulate the secretion of other hormones and of exocrine enzymes (Adrian et al., 1978; Roncoroni et al., 1983; Csaba and Dournaud, 2001; Wierup et al., 2002; Heller et al., 2005).

The earliest morphological signs of pancreas development are observed at approximately embryonic day 9.5 (E9.5) as dorsal and ventral protrusions of the primitive gut epithelium that will later fuse to form the definitive pancreas (reviewed in Edlund, 2002; Jørgensen et al., 2007). Concomitantly, glucagon-producing cells are the first endocrine cells detected (Herrera et al., 1991; Teitelman et al., 1993; Upchurch et al., 1994). At embryonic day 10.5 (E10.5), a few insulin-producing cells appear, often co-expressing the glucagon hormone (Teitelman et al., 1993). At E14, a peak of endocrine cell genesis leads to the generation of numerous fully differentiated insulin-expressing beta-cells and glucagon-producing alpha-cells. Endocrine cells organize themselves into small aggregates and, within the next $24 \mathrm{~h}$, the first somatostatin-producing delta-cells emerge (Pictet et al., 1972). Finally, at E18, shortly before birth, PP-expressing PP-cells differentiate, while endocrine cells begin to form well-organized islets of Langerhans.

Until recently, the mechanisms underlying the generation of these different endocrine cell types were not well understood, but lineage studies and the generation of mice deficient for a number of pancreatic transcription factors have provided major insight into these processes. Besides, genetic manipulations, such as loss-, but also gain-of-function approaches, have permitted researchers to better define the function of such factors, including Sox9, Pdx1, Ngn3, IA1, Pax4, Arx, Nkx2.2, Nkx6.1, Nkx6.2, Pax6, and MafA.

Hence, Sox9, a member of the Sox gene family, is expressed in $\mathrm{Pdx} 1^{+}$cells of the pancreatic epithelium from E9.0 onwards. At E14.5, after the second transition its expression becomes restricted to non-differentiating cells expressing low levels of Pdx $1^{+}$and is absent in hormone expressing cells. Postnatally, Sox9 is localized in centroacinar cells and a small subset of ductal epithelial cells (Seymour et al., 2007). Several findings supported the notion that Sox9 labels pancreatic progenitor cells: (1) Sox9 expression appears unchanged in Ngn3 and Nkx6.1-null mice, (2) in transgenic mice in which $\mathrm{Pdx} 1^{+}$progenitor cells are artificially maintained in their progenitor state, Sox9 expression remains abnormally sustained, and (3) Sox9 is found co-expressed with the proendocrine transcription factor Ngn3 at E15.5, but lack in cells expressing mature islet markers, such as Nkx2.2 and Isl1. Lastly, the targeted dele- tion of Sox9 in Pdx $1^{+}$progenitors was found to induce a decrease in the endocrine cell mass concomitantly to a premature differentiation into cells expressing glucagon and Isl1. Therefore, during early pancreas development, Sox9 seemingly marks a pool of pluripotent progenitor cells in which its activities appear crucial to keep such cells in a proliferative state and thereby prevent their premature differentiation (Lynn et al., 2007; Seymour et al., 2008).

Similar to Sox9, Pdx1, a homeodomain-containing transcription factor, is expressed as early as E8.5 in the dorsal and ventral endoderm, posterior to the stomach and duodenal epithelium. Subsequently, $P d x 1$ expression progressively becomes restricted to the beta-cell lineage in which it controls glucose-stimulated insulin secretion (Ohlsson et al., 1993; Stoffers et al., 1999; Guz et al., 1995). Lineage tracing experiments have demonstrated that mature pancreatic cells derive from $P d x 1$-expressing progenitor cells (Gu et al., 2003). This was further confirmed by the pancreatic agenesis detected in Pdx1-deficient mice (Offield et al., 1996). The conditional inactivation of this factor at different developmental stages, as well as in mature beta-cells, underscored its requirement to specify, but also maintain, the beta-cell phenotype (Ahlgren et al., 1998; Holland et al., 2005). Furthermore, Gannon et al. (2008) observed that the inactivation of $P d x 1$ in late-gestational beta-cells led to a decrease in the proliferation of insulin-producing cells concomitantly with an augmentation in proliferation of glucagon-producing cells. These results suggest that Pdx1 function is necessary for the genesis and maintenance of beta-cells, but also for late-gestational regulation of the proper endocrine cell numbers (Gannon et al., 2008). Interestingly, using a Tet-off approach, the conditional down-regulation of $P d x 1$ was found to provoke an arrest of beta-cell development, but also alterations in acinar cell genesis. One likely explanation may be the absence of Ptf1a, a factor downstream of Pdx1 known to play a crucial role in acinar cell development (Hale et al., 2005). During early pancreas development, Ptf1a is expressed throughout the pancreatic epithelium, whereas, at later stages, it is exclusively detected in acinar cells (Krapp et al., 1996). Consistently, mice with targeted ablation of Ptf1a do not develop any acinar cells, whereas the four endocrine cell types are present albeit misallocated in the splenic mesenchyme (Krapp et al., 1998). The combined loss of Pdx1 and $P t f 1 a$ in mice leads to alterations similar to those seen in $P d x 1$ single mutant mice, suggesting that Ptf1a acts downstream of $P d x 1$ (Burlison et al., 2008). However, recent findings revealed that Ptf1a also interacts with the $P d x 1$ promoter thereby potentiating $P d x 1$ expression in early pancreatic progenitors and later in acinar cells (Wiebe et al., 2007).

Unlike Pdx1 playing pleiotropic roles during the development of the pancreas, the bHLH transcription factor, Ngn3 exclusively acts on the differentiation of the endocrine tissue. Accordingly, lineage tracing analyses indicated that endocrine cells are derived from cells that expressed Ngn3 (Gu et al., 2002). Detectable from E8.5 onward, Ngn3-expression peaks around E15.5 and is maintained at lower levels in mature endocrine cells. Loss-of-function experiments have demonstrated the requirement of $\mathrm{Ngn3}$ for the specification of all enteroendocrine and endocrine lineages (Gradwohl et al., 2000; Jenny et al., 2002; Gu et al., 2003). Interestingly, the ablation of $\mathrm{Ngn} 3$ in adult Pdx $1^{+}$cells was associated with reduced expression of several Ngn3 target genes and found to result in impaired islet function, outlining the importance of sustained Ngn3 expression in mature endocrine cells (Wang et al., 2009). Furthermore, gain-of-function analyses established its potential in promoting endocrine cell differentiation (Schwitzgebel et al., 2000; Heremans et al., 2002). Hence, the ectopic expression of Ngn3 in Pdx1-expressing cells leads to a premature onset of endocrine differentiation resulting in the near exclusive genesis of glucagon-producing cells (Apelqvist et al., 1999; Grapin-Botton et al., 2001). In the light of these results, Ngn3 was initially con- 

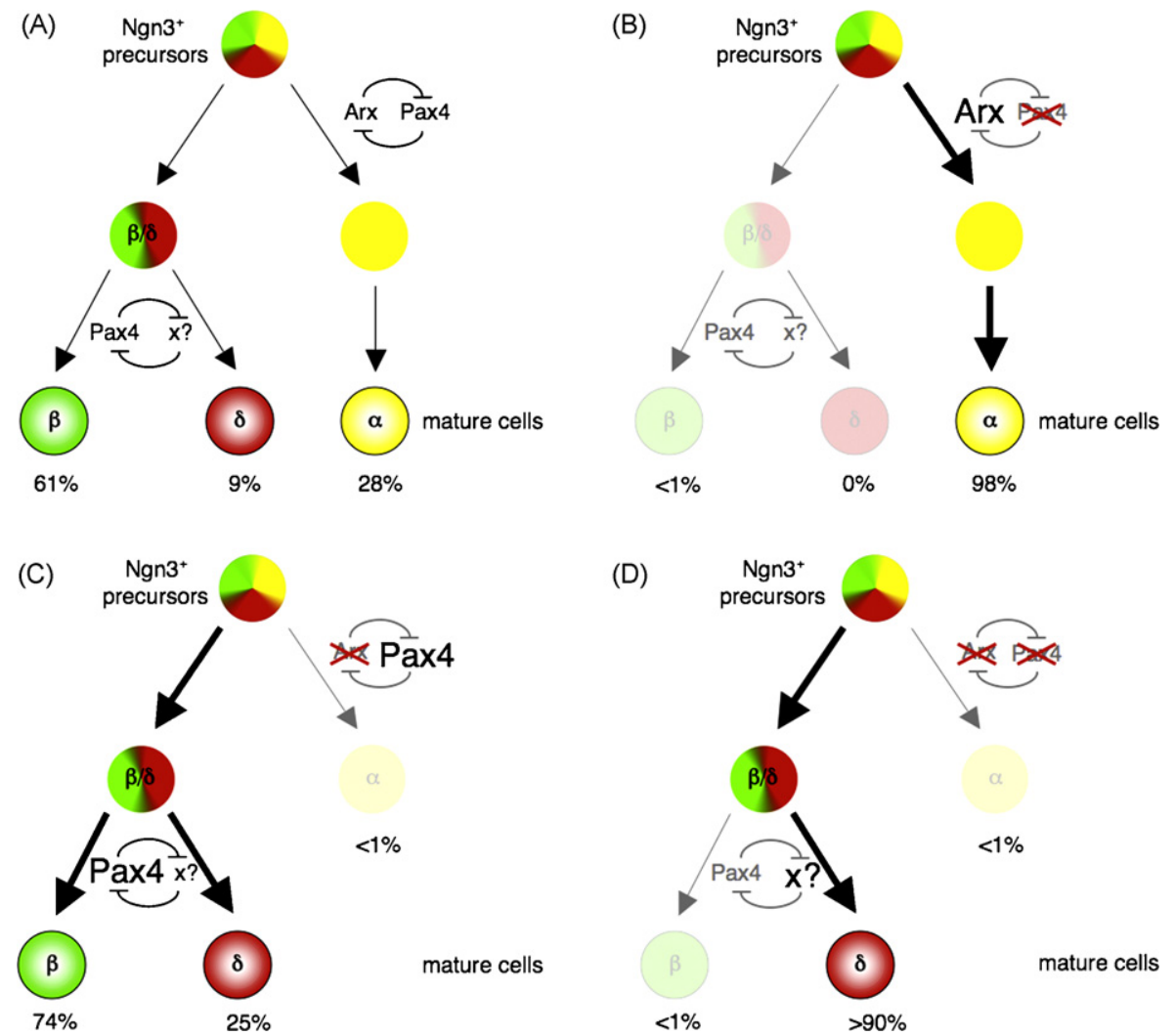

(D)

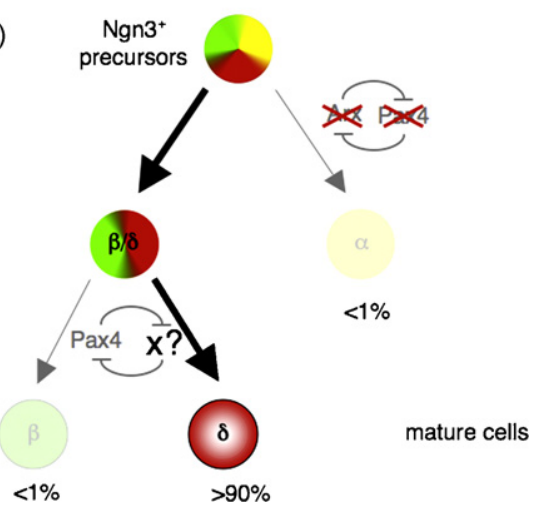

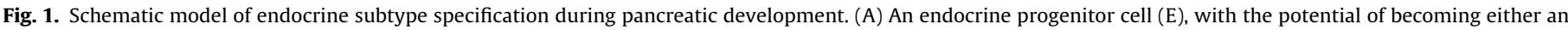

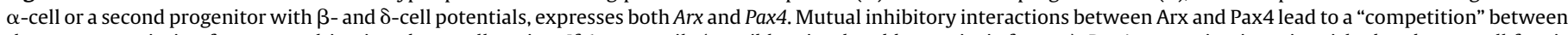

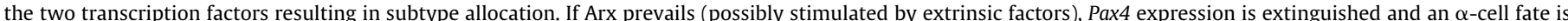

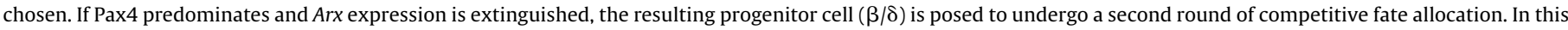

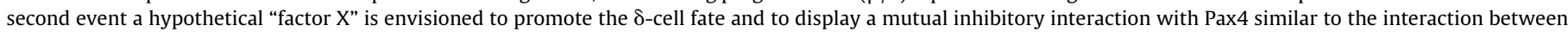

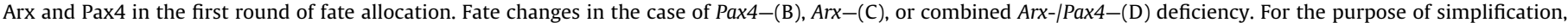
PP-cells are not figured.

sidered as a proendocrine factor. However, recent data brought additional insight into the function of Ngn3. Indeed, Villasenor et al. (2008) showed that Ngn3 expression occurs in two distinct temporal waves, correlating with the first and secondary transition as described by Pictet et al. (1972), thereby generating "early" and "late" born endocrine cells owning different developmental potentials (Villasenor et al., 2008). Interestingly, the temporal relevance of Ngn3 expression has also been outlined recently by Johansson et al. (2007). Briefly, the authors crossed a Pdx1-controlled, tamoxifen-inducible Ngn3 mouse line with Ngn3-deficient animals and specifically activated Ngn3 in the pancreas through tamoxifen treatment at different developmental stages. It was thereby established that early $\mathrm{Ngn}^{+}$cells exclusively give rise to alpha-cells. Importantly, the activation of Ngn3 at later developmental stages was found to successively promote the genesis of beta-, PP- (after E11.5) or delta- (after E14.5) cells, while the competence to give rise to alpha-cells progressively decreases.

Following Ngn3 activation, several additional factors acting in the endocrine cell allocation have been characterized. Hence, the zinc-finger-containing transcription factor insulinoma-associated antigen 1 (IA-1) was found to represent a direct downstream target of Ngn3 and to act in the initial steps underlying endocrine cell differentiation. Endocrine cells are still detected in IA-1 mutant pancreata, but the majority of these do not express any hormones (Gierl et al., 2006). Unlike Ngn3, the ectopic expression of IA1 in duct cells is not sufficient to induce the endocrine specification program, although the co-expression of Ngn3 and IA1 was found to significantly enhance the efficiency of the in vitro duct-to-endocrine transdifferentiation as compared to ectopic $\mathrm{Ngn3}$ expression only (Mellitzer et al., 2006).

Among the aforementioned factors involved in early endocrine cell differentiation, Arx and Pax4 were found to play key roles in the specification of the endocrine cell subtypes, Arx promoting the alpha-/PP-cell fates, whereas Pax4 induces the beta-/deltacell lineages (Fig. 1A-C). Indeed, in Pax4-deficient pancreata, beta-/delta-cells do not develop, while a proportional increase in alpha-cell numbers is observed (Sosa-Pineda et al., 1997). Conversely, upon the loss of Arx, an increase in both beta- and delta-cell populations is noticed while alpha-cells are absent (Collombat et al., 2003). It is worth noting that in both instances, the total islet cell numbers are found unchanged as compared to wild-type pancreata. Closer examination indicated that Arx and Pax4 factors exhibit antagonistic roles on the specification of the endocrine subtype destinies through an inhibitory, cross-regulatory circuit that controls the transcriptional state of these two genes. The combined loss of Pax4 and $\operatorname{Arx}$ (Fig. 1D) do not result in an arrest in the differentiation of all four endocrine cell types, but rather in the depletion of betaand alpha-cells, while the delta-cell population is increased and the PP-cell content is unaltered (Collombat et al., 2005). It was therefore concluded that Pax4 is not required to directly specify the beta/delta-cell destinies, but rather acts by inhibiting the alpha-cell fate through the inhibition of Arx expression.

In an effort to further define the transcriptional network underlying the development of the pancreas, the role of $\mathrm{Nkx2.2,} \mathrm{a}$ homeodomain-containing factor belonging to the NK-class, was characterized. Acting early during development, Nkx2.2 was found to play a preponderant function especially in the specification of 
the beta-cell lineage. Indeed, in mature islets, Nkx2.2 labels alpha-, beta- and PP-cells. Accordingly, mice depleted in Nkx2.2 display a loss of beta-cells, as well as reduced alpha- and PP-cell contents, whereas the numbers of delta-cells remain unaffected. It is worth noting that the ghrelin-expressing cell population appears considerably augmented in such animals (Sussel et al., 1998; Prado et al., 2004). The analysis of Pax4-/Nkx2.2-double-nullizygous mice revealed alterations similar to those observed in pancreata of Nkx2.2-1- mutant mice, indicating that Pax4 may act downstream of $N k x 2.2$. This was further supported by the lack of alteration in the expression levels of $N k x 2.2$ in Pax4-deficient mice.

Nkx6.1, another early marker of the pancreatic epithelium also belonging to the Nkx subfamily, is first detected at E9.5. Its expression is initially detectable in $\mathrm{Ngn}^{+}$endocrine precursor cells, but becomes restricted to mature beta-cells where it was found to be required for proper insulin secretion (Oster et al., 1998; Sander et al., 2000). Indeed, mice lacking $N k x 6.1$ exhibit a dramatic reduction in mature beta-cells, while other islet cell subtypes develop normally (Sander et al., 2000). Interestingly, early insulin ${ }^{+}$cells emerging during the first transition are not affected, suggesting a decisive role for Nkx6.1 for the generation of "late-born" mature beta-cells originating from the second transition (Henseleit et al., 2005). $N k x 6.2$, a paralog to $N k x 6.1$, displays a similar expression pattern compared to $N k x 6.1$, but in contrast to the latter, it is not detected in adult beta-cells (Henseleit et al., 2005; Pedersen et al., 2005). Importantly, Nkx6.2 mutant mice do not present any obvious phenotype, whereas mice deficient for both $N k x 6.1$ and $N k x 6.2$ exhibit similar alterations as compared to Nkx6.1-mutant mice (loss of mature beta-cells), but also a drastic reduction in glucagon ${ }^{+}$cells, indicating an additional involvement of the Nkx-factors in alphacell formation (Henseleit et al., 2005). Notably, in Nkx6.1-1- mice, misexpression of $N k x 6.2$ in $\mathrm{Pdx} 1^{+}$cells was found to rescue betacell development, indicating that both factors possess redundant activities for beta-cell differentiation (Nelson et al., 2007).

Besides Pax4, another member of the Pax gene family, Pax6, plays an important role in islet cell differentiation. Pax6 is expressed in all endocrine hormone-producing cells throughout pancreas morphogenesis. Conventional knockout of Pax6 in mice revealed its requirement for the development of all four endocrine cell subtypes, as well as its involvement in forming well-structured islets of Langerhans (St-Onge et al., 1997; Sander et al., 1997). Interestingly, using conditional ablation of Pax6 in mice, an additional role of this gene in maintaining the postnatal beta-cell phenotype was outlined, as such, mice displayed a diabetic condition associated with hypoinsulinemia (Ashery-Padan et al., 2004).

Numerous additional factors were characterized for their involvement in the maintenance of the beta-cell identity, including representatives of the Maf gene family (MafA, MafB and c.Maf) that were also shown to act in the terminal differentiation of beta-, but also alpha-cells. For instance, MafA was found to directly interact with the promoter of the insulin gene and to transactivate insulin expression (Matsuoka et al., 2003; Aramata et al., 2005; Zhao et al., 2005). Its expression is initiated at E13.5 and is restricted to insulin ${ }^{+}$cells during embryogenesis as well as throughout adulthood (Matsuoka et al., 2004). Consistently, mice deficient for MafA develop diabetes mellitus accompanied with a significant decrease in circulating insulin levels and, in addition, abnormal islet architecture. Isolated MafA-deficient insulin ${ }^{+}$cells are unable to secrete insulin upon glucose challenge, indicating a beta-cell autonomous defect in glucose-stimulated insulin secretion (Zhang et al., 2005). Moreover, the ectopic expression of MafA in the embryonic chicken endoderm, as well as in non-pancreatic cell cultures, was found to be sufficient to promote insulin secretion (Matsuoka et al., 2007; Artner et al., 2008). Altogether, this non-extensive description of the major players acting to specify the different endocrine cell subtypes outlines the complexity of the mechanisms involved. In order to exploit these findings for the in vitro or in vivo genesis of insulin-producing beta-cells, gaining more insight into the endocrine differentiation program, but also into the interplay of the different actors, will represent a challenge for the years to come.

\section{Mechanisms of beta-cell replenishment}

Among the several approaches envisaged to treat diabetesrelated beta-cell insufficiency, the in vivo regeneration of insulin-producing beta-cells appears of great potential. The fact that the adult beta-cell mass is not static, but fluctuates in response to changing physiological conditions, such as pregnancy and insulin-resistance, underscores the activity of adaptive mechanisms (Lingohr et al., 2002; Bonner-Weir, 2000). Furthermore, several approaches, including surgical ablation of pancreatic tissue as well as partial duct ligation (PDL), were found to initiate endogenous regenerative programs acting to replace missing cells. These findings raise the question of the cellular origin of neogenerated cells. Using a pulse-chase labeling of beta-cells, Dor et al. (2004) established that, throughout adult life, or following partial pancreatectomy, new beta-cells arise from pre-existing beta-cells rather than from any other cell subtype. Similar results were obtained after the diphtheria-toxin-mediated ablation of the beta-cell mass: treated mice recovered from hyperglycemia through the genesis of new beta-cells that mainly originated from surviving beta-cells (Nir et al., 2007). Using sequential administration of CldU and IdU, Teta et al. were able to label cells that had undergone more than one round of cell division and therefore identify potential stem or progenitor cells. Focusing on pancreatic beta-cells, they observed that repeatedly dividing progenitors did not contribute to the adult beta-cell mass neither under physiological conditions nor following 50\% pancreatectomy nor during pregnancy (Teta et al., 2007). However, several other studies suggested alternative origins for beta-cells during pancreas regeneration, thereby encouraging the pancreatic stem cell controversy.

One of the first hints for the contribution of non-beta-cells to the beta-cells mass was provided by Wang et al. (1995). Provoking a regenerative response in rats through partial duct ligation combined with BrdU pulse-chase labeling, the results obtained indicated that proliferation could not fully account for the drastic beta-cell hyperplasia. It was therefore concluded that multipotent precursors and/or stem cells may be implicated in these regeneration events. Ductal cells were thought to be at the origin of such neogenerated cells due to the detection of metaplastic cells expressing both ductal and beta-cell marker and the increased proliferative activity noted around ducts. Interestingly, in 2008, a pioneering study from Heimberg's Laboratory conclusively established the involvement of duct-lining precursor cells in pancreatic islet regeneration following PDL. Besides the mechanism of selfduplication of pre-existing beta-cells, the authors also identified cells re-expressing the proendocrine gene Ngn3 in the ductal lining. Such isolated cells were found capable to give rise to all four endocrine cell subtypes (Xu et al., 2008). Along the same vein, Inada et al. were able to trace the lineage of newly formed beta-cells following PDL in adult mice. They thereby determined that duct cells could indeed give rise to islets and acinar cells. Remarkably, in noninjured neonates, the naturally occurring postnatal increase in islet cell mass was also partially attributed to duct cell conversion (Inada et al., 2008).

Altogether, the findings that beta-cells can be regenerated by replication of pre-existing beta-cells, but also through the conversion of exocrine cells opens new perspectives for the treatment of diabetes. However, new questions arise, especially concerning the nature of the extrinsic and/or intrinsic signals implicated into such conversion. Specifically, whether PDL induces 


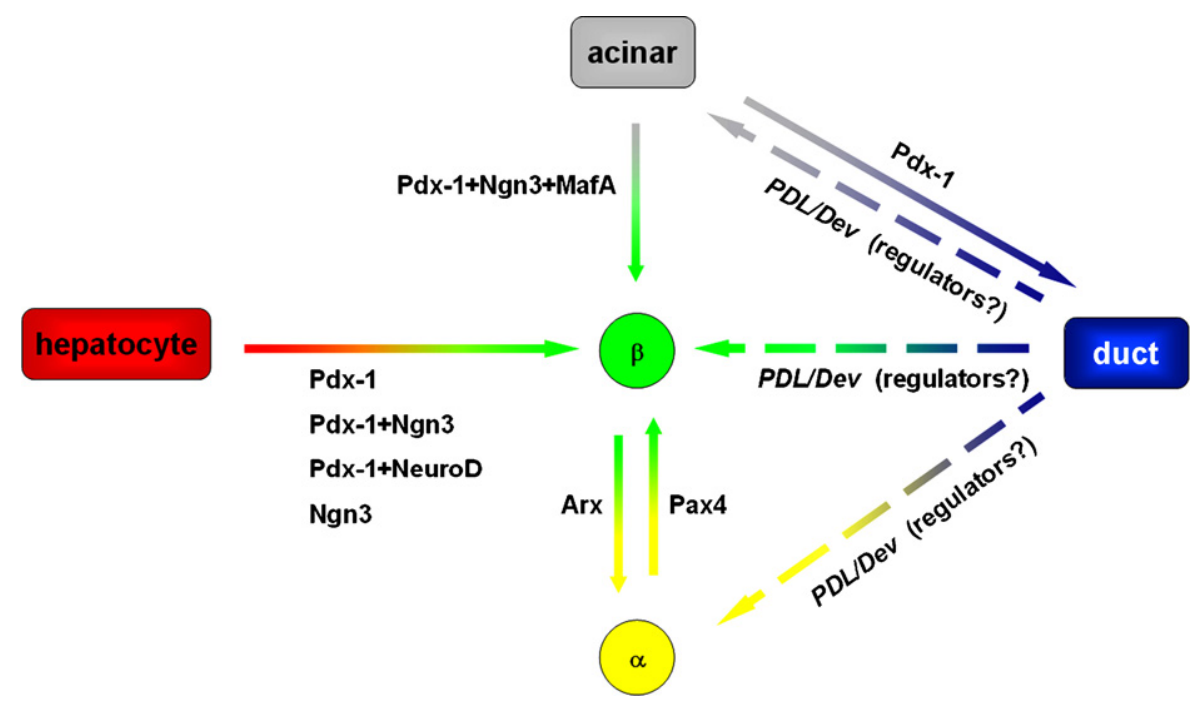

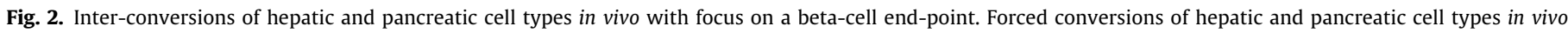

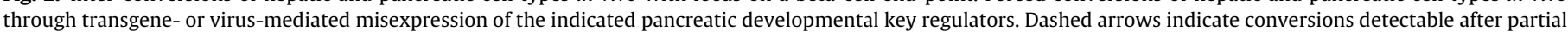

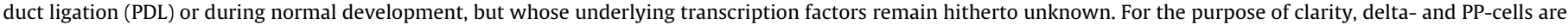
not figured.

the reprogramming of duct-lining cells or outlines the presence of precursor cells will have to be determined. Deciphering the detailed mechanisms underlying beta-cell neogenesis from pancreatic cells and finding ways to chemically induce such conversion will be one of the greatest challenges facing the future of diabetes research.

\section{Reprogramming into pancreatic cells}

In the last years, several studies outlined an unsuspected plasticity of mature pancreatic cells (Tosh and Slack, 2002; Eberhard and Tosh, 2008). Such findings opened new avenues for the treatment of type 1 diabetes since it was established that particular pancreatic cell types may be forced to adopt an alternate phenotype through the misexpression of selected transcription factors. The analysis of the genetic determinants underlying the genesis of the different cell subtypes and the determination of mechanisms by which a particular fate is specified at the expense of another during the development is therefore crucial, as such knowledge may be used to induce specific cells to adopt another identity. This research could (1) be applied to the programming of stem or progenitor cells into endocrine cells in vitro, and (2) lay the basis towards the ultimate goal of reprogramming abundant and easily accessible patient-specific human cells, such as fibroblasts, blood cells or adipocytes, into becoming insulin-producing betacells.

Numerous protocols aiming at differentiating ES-cells have been reviewed previously (Nir and Dor, 2005; D’amour et al., 2006; Oliver-Krasinski and Stoffers, 2008). In the following, we will therefore focus on the in vivo reprogramming of pancreatic and non-pancreatic cells into endocrine cells, with emphasis on the beta-cell end-point (Fig. 2).

As all pancreatic cells derive from $P d x 1$-expressing progenitor cells (Gu et al., 2003), this factor was the focus of several studies aiming at converting various cell types into pancreatic cells (Ber et al., 2003; Taniguchi et al., 2003; Shternhall-Ron et al., 2007). Hence, following partial pancreatectomy or PDL, both characterized by regeneration of pancreatic cells, $P d x 1$ was found ectopically expressed in mature ductal structures. This suggests that Pdx1 may play a crucial role in regenerative processes and direct the conversion of different pancreatic cell subtypes. To conclusively determine its function, a cre-mediated conditional misexpression approach was used to ectopically express $P d x 1$ in acinar cells. Thus, persistent $P d x 1$ expression in acinar cells was found to induce their conversion into cells exhibiting a ductal identity (Miyatsuka et al., 2006). Since both the liver and pancreas arise from adjacent regions of the embryonic endoderm, it was thought that these closely related tissues may be interconverted. The transient expression of the Pdx1 homolog Xlhbox8 in Xenopus liver cells, as well as in cultured hepatocytes, was thereby found to induce the reprogramming of these cells into pancreatic exocrine and endocrine cell types (Horb et al., 2003). Similar results were obtained following adenoviral-mediated misexpression of $P d x 1$ in the mouse liver (Ferber et al., 2000; Ber et al., 2003; Shternhall-Ron et al., 2007). This transient misexpression of $P d x 1$ was found sufficient to prevent streptozotocin-induced hyperglycemia in mice for several months. The concomitant adenoviral application of two factors, Pdx1 and Ngn3 or NeuroD in the liver of mice, was likewise associated with the conversion of hepatic cells into insulin-producing cells, and to a significant amelioration of glucose-tolerance (Kaneto et al., 2005). Interestingly, a study from Yechoor et al. (2009) revealed that the endocrine specification factor Ngn3 alone has likewise the competence to induce a pancreatic differentiation program when ectopically expressed in the liver. The adenoviral application of Ngn3 combined with the islet growth factor betacellulin into the liver of streptozotocin-diabetic mice led to the emergence of all four major islet cell types including insulinexpressing cells possesing glucose responsive properties. Lineage tracing experiments revealed both parenchymal hepatocytes and multipotential hepatic progenitor cells to be the origin. Interestingly, parenchymal hepatocytes gave rise to insulin ${ }^{+}$cells only transiently, thereby retaining their hepatic properties. In contrast, neogenerated islet-like cells originating from the progenitor population displayed the full set of endocrine transcription factors acting downstream of Ngn3 during pancreas development and maintained their islet characteristics even 6 months post-Ngn3 injection. This study impressively demonstrated how a single transcription factor induces a lineage-switch towards a pancreatic endocrine fate when ectopically expressed in endodermal derived hepatic progenitor cells.

Focusing on the directed generation of endocrine cells, several recent studies concentrated on the characterization of addi- 
tional transcription factors known for their involvement in the specification of the different islet cell lineages during pancreas morphogenesis. Hence, using loss- and gain-of-function approaches, the crucial and opposed roles of Pax4 and Arx in specifying the fates of the different endocrine subtypes were outlined. While Pax 4 promotes the beta/delta-cell lineages, Arx drives progenitor cells towards the alpha/PP-cell fate (Collombat et al., 2003). Aiming to determine whether these factors may not only act during pancreas morphogenesis, but also in adult animals, the expression of Arx was triggered in adult beta-cells using an inducible Cre/Lox system combined with lineage tracing. It was thereby demonstrated that the ectopic expression of Arx in adult beta-cells forces these to adopt alternative alpha- or PP-cell identities (Collombat et al., 2007). This discovery was of fundamental importance in the context of beta-cell-based therapy as it implied that the opposite conversion might be achieved, that is, to generate beta-cells from other endocrine cells misexpressing the Arx-counterpart, Pax4. To verify this hypothesis, the ectopic expression of Pax4 was induced, notably, in glucagon-producing cells using the Cre-loxP system (Collombat et al., 2009). Lineage tracing experiments indicated a conversion of these glucagon ${ }^{+}$cells into cells exhibiting most features of true beta-cells. The resulting glucagon deficiency was found to induce a compensatory and continuous glucagon ${ }^{+}$cell neogenesis requiring the re-expression of the proendocrine gene Ngn3. However, such cells failed to correct the hypoglucagonemia as they subsequently acquired a beta-cell phenotype upon Pax4 misexpression. Notably, this cycle of neogenesis/conversion was found sufficient to restore a functional beta-cell mass in animals with chemically induced type 1 diabetes. Altogether, this study revealed that a single factor is sufficient to promote both a beta-cell fate during pancreas morphogenesis, but also a beta-cell phenotype in differentiated pancreatic cells. Along the same line, using the extensive findings from diverse loss-of-function analyses, Zhou et al. (2008) highlighted nine transcription factors displaying alterations in beta-cell function or number when mutated. The adenoviral infection of combinations of some of these factors into the exocrine pancreas of adult mice resulted in the conversion of acinar cells into insulin-secreting cells. The combination of factors with the highest inductive efficiency consisted of Pdx1, Ngn3 and MafA. Such insulin-secreting cells were morphologically indistinguishable from endogenous beta-cells and expressed all known beta-cell molecular markers. Furthermore, streptozotocin-treated mice recovered from diabetes after the injection of the three factors. Notably, this reprogramming of acinar cells did not involve any dedifferentiation or proliferating steps, suggesting a process of direct transdifferentiation (Zhou et al., 2008). Interestingly, Pdx1 and MafA were required only transiently as they induced their endogenous homologues. Ngn3 expression was found down-regulated 1 month post-infection, thereby mimicking its transient expression pattern as normally seen during embryonic development.

This study clearly outlined the stable and exclusive conversion of one cell type into another. Interestingly, using the same factors, it was not possible to force the acquisition of the beta-cell identity using muscle and fibroblast cells as starting material. The close relation and epigenetic similarities of acinar- and beta-cells might be a prerequisite for a successful conversion. This raises the question of whether reprogramming of abundant and easily accessible patientspecific human cells, such as fibroblasts, blood cells or adipocytes, into insulin-producing beta-cells might be achieved. It is likely that such cells would have to be dedifferentiated to some extent prior to force them to acquire an alternative identity. Towards this goal, the recently reported reprogramming of human skin cells into induced pluripotent stem cells (iPS) suggests the possibility of generating patient-specific pluripotent stem lines that could ultimately be used for further differentiation into insulin-producing beta-cells (Takahashi and Yamanaka, 2006).

\section{Conclusions and future aspects}

An active research aiming at characterizing the mechanisms underlying normal and pathological pancreas development uncovered numerous key factors and allowed the elucidation of some of their mutual interactions. This knowledge was/is used as a roadmap for the directed in vivo and in vitro generation of functional betacells and raises hopes for a suitable beta-cell replacement-therapy in order to improve type 1 , but also type 2 , diabetes treatment. However, despite these promising progresses, we need to gain further insight into the complex transcriptional network and interplay governing the differential development of the four endocrine cell subtypes. It is also obvious that additional factors expressed in progenitors, as well as mature beta-cells, have to be identified in order to design rational protocols faithfully mimicking natural islet cell genesis. Comprehensive chip-assay and in situ hybridization screens already widened our view of the participating genes (Zhou et al., 2007). A closer examination of their function and mutual relationship will doubtlessly contribute to our understanding of the orchestrated interplay underlying pancreas development and improve the protocols aiming at generating fully differentiated and stable cells exhibiting a beta-cell phenotype from ES-cells, iPS cells or other cell types.

\section{Acknowledgements}

We wish to thank Dr. K. Al-Hasani for his thorough reading of our manuscript and important suggestions. The authors are supported by the Max-Planck Society, the Dr. H. Storz and Alte Leipziger foundation, the Juvenile Diabetes Research foundation (26-2008-639), the INSERM AVENIR program, the INSERM, and the NIH Beta Cell Biology Consortium (U19 DK 072495-01).

\section{References}

Adrian, T.E., Bloom, S.R., Hermansen, K., Iversen, J., 1978. Pancreatic polypeptide glucagon and insulin secretion from the isolated perfused canine pancreas. Diabetologia 14, 413-417.

Ahlgren, U., Jonsson, J., Jonsson, L., Simu, K., Edlund, H., 1998. Beta-cell-specific inactivation of the mouse Ipf1/Pdx1 gene results in loss of the beta-cell phenotype and maturity onset diabetes. Genes Dev. 12,1763-1768.

Apelqvist, A., Li, H., Sommer, L., Beatus, P., Anderson, D.J., Honjo, T., Hrabe De Angelis, M., Lendahl, U., Edlund, H., 1999. Notch signalling controls pancreatic cell differentiation. Nature 400, 877-881.

Aramata, S., Han, S.I., Yasuda, K., Kataoka, K., 2005. Synergistic activation of the insulin gene promoter by the beta-cell enriched transcription factors MafA, Beta2, and Pdx1. Biochim. Biophys. Acta 1730, 41-46.

Artner, I., Hang, Y., Guo, M., Gu, G., Stein, R., 2008. MafA is a dedicated activator of the insulin gene in vivo. J. Endocrinol. 198, 271-279.

Ashery-Padan, R., Zhou, X., Marquardt, T., Herrera, P., Toube, L., Berry, A., Gruss, P., 2004. Conditional inactivation of Pax6 in the pancreas causes early onset of diabetes. Dev. Biol. 269, 479-488.

Ber, I., Shternhall, K., Perl, S., Ohanuna, Z., Goldberg, I., Barshack, I., Benvenisti-Zarum, L., Meivar-Levy, I., Ferber, S., 2003. Functional, persistent, and extended liver to pancreas transdifferentiation. J. Biol. Chem. 278, 31950-31957.

Bonner-Weir, S., 2000. Life and death of the pancreatic beta cells. Trends Endocrinol Metab. 11, 375-378.

Burlison, J.S., Long, Q., Fujitani, Y., Wright, C.V., Magnuson, M.A., 2008. Pdx1 and Ptf1a concurrently determine fate specification of pancreatic multipotent progenitor cells. Dev. Biol. 316, 74-86.

Collombat, P., Hecksher-Sorensen, J., Broccoli, V., Krull, J., Ponte, I., Mundiger, T., Smith, J., Gruss, P., Serup, P., Mansouri, A., 2005. The simultaneous loss of Arx and Pax4 genes promotes a somatostatin-producing cell fate specification at the expense of the alpha- and beta-cell lineages in the mouse endocrine pancreas. Development 132, 2969-2980.

Collombat, P., Hecksher-Sorensen, J., Krull, J., Berger, J., Riedel, D., Herrera, P.L., Serup, P., Mansouri, A., 2007. Embryonic endocrine pancreas and mature beta cells acquire alpha and PP cell phenotypes upon Arx misexpression. J. Clin. Invest. 117, 961-970.

Collombat, P., Mansouri, A., Hecksher-Sorensen, J., Serup, P., Krull, J., Gradwohl, G., Gruss, P., 2003. Opposing actions of Arx and Pax4 in endocrine pancreas development. Genes Dev. 17, 2591-2603.

Collombat, P., Xu, X., Ravassard, P., Sosa-Pineda, B., Dussaud, S., Billestrup, N., Madsen, O.D., Serup, P., Heimberg, H., Mansouri, A., 2009. The ectopic expression of Pax4 in the mouse pancreas converts progenitor cells into alpha and subsequently beta cells. Cell 7138 (3), 449-462. 
Csaba, Z., Dournaud, P., 2001. Cellular biology of somatostatin receptors. Neuropeptides 35, 1-23.

D’amour, K.A., Bang, A.G., Eliazer, S., Kelly, O.G., Agulnick, A.D., Smart, N.G., Moorman, M.A., Kroon, E., Carpenter, M.K., Baetge, E.E., 2006. Production of pancreatic hormone-expressing endocrine cells from human embryonic stem cells. Nat. Biotechnol. 24, 1392-1401.

Dor, Y., Brown, J., Martinez, O.I., Melton, D.A., 2004. Adult pancreatic beta-cells are formed by self-duplication rather than stem-cell differentiation. Nature 429 , 41-46.

Eberhard, D., Tosh, D., 2008. Transdifferentiation and metaplasia as a paradigm for understanding development and disease. Cell. Mol. Life Sci. 65, 33-40.

Edlund, H., 2002. Pancreatic organogenesis-developmental mechanisms and implications for therapy. Nat. Rev. Genet. 3, 524-532.

Ferber, S., Halkin, A., Cohen, H., Ber, I., Einav, Y., Goldberg, I., Barshack, I., Seijffers, R., Kopolovic, J., Kaiser, N., Karasik, A., 2000. Pancreatic and duodenal homeobox gene 1 induces expression of insulin genes in liver and ameliorates streptozotocin-induced hyperglycemia. Nat. Med. 6, 568-572.

Gannon, M., Ables, E.T. Crawford, L., Lowe, D., Offield, M.F., Magnuson, M.A., Wright, C.V., 2008. Pdx1 function is specifically required in embryonic beta cells to generate appropriate numbers of endocrine cell types and maintain glucose homeostasis. Dev. Biol. 314, 406-417.

Gierl, M.S., Karoulias, N., Wende, H., Strehle, M., Birchmeier, C., 2006. The zinc-finger factor Insm 1 (IA-1) is essential for the development of pancreatic beta cells and intestinal endocrine cells. Genes Dev. 20, 2465-2478.

Githens, S., Schexnayder, J.A., Moses, R.L., Denning, G.M., Smith, J.J., Frazier, M.L., 1994. Mouse pancreatic acinar/ductular tissue gives rise to epithelial cultures that are morphologically, biochemically, and functionally indistinguishable from interlobular duct cell cultures. In Vitro Cell. Dev. Biol. Anim. 30A, 622635.

Gradwohl, G., Dierich, A., Lemeur, M., Guillemot, F., 2000. Neurogenin3 is required for the development of the four endocrine cell lineages of the pancreas. Proc. Natl. Acad. Sci. U.S.A. 97, 1607-1611.

Grapin-Botton, A., Majithia, A.R., Melton, D.A., 2001. Key events of pancreas formation are triggered in gut endoderm by ectopic expression of pancreatic regulatory genes. Genes Dev. 15, 444-454.

Gu, G., Brown, J.R., Melton, D.A., 2003. Direct lineage tracing reveals the ontogeny of pancreatic cell fates during mouse embryogenesis. Mech. Dev. 120, 35-43.

Gu, G., Dubauskaite, J., Melton, D.A., 2002. Direct evidence for the pancreatic lineage: NGN3+ cells are islet progenitors and are distinct from duct progenitors. Development 129, 2447-2457.

Guz, Y., Montminy, M.R., Stein, R., Leonard, J., Gamer, L.W., Wright, C.V., Teitelman, G., 1995. Expression of murine STF-1, a putative insulin gene transcription factor, in beta cells of pancreas, duodenal epithelium and pancreatic exocrine and endocrine progenitors during ontogeny. Development 121, 11-18.

Hale, M.A., Kagami, H., Shi, L., Holland, A.M., Elsasser, H.P., Hammer, R.E., Macdonald, R.J., 2005. The homeodomain protein PDX1 is required at mid-pancreatic development for the formation of the exocrine pancreas. Dev. Biol. 286, 225237.

Heller, R.S., Jenny, M., Collombat, P., Mansouri, A., Tomasetto, C., Madsen, O.D., Mellitzer, G., Gradwohl, G., Serup, P., 2005. Genetic determinants of pancreatic epsilon-cell development. Dev. Biol. 286, 217-224.

Henseleit, K.D., Nelson, S.B., Kuhlbrodt, K., Hennings, J.C., Ericson, J., Sander, M., 2005. NKX6 transcription factor activity is required for alpha- and beta-cell development in the pancreas. Development 132, 3139-3149.

Heremans, Y., Van De Casteele, M., In't Veld, P., Gradwohl, G., Serup, P., Madsen, O., Pipeleers, D., Heimberg, H., 2002. Recapitulation of embryonic neuroendocrine differentiation in adult human pancreatic duct cells expressing neurogenin 3. J. Cell. Biol. 159, 303-312.

Herrera, P.L., Huarte, J., Sanvito, F., Meda, P., Orci, L., Vassalli, J.D., 1991. Embryogenesis of the murine endocrine pancreas: early expression of pancreatic polypeptide gene. Development 113, 1257-1265.

Holland, A.M., Gonez, L.J., Naselli, G., Macdonald, R.J., Harrison, L.C., 2005. Conditional expression demonstrates the role of the homeodomain transcription factor Pdx1 in maintenance and regeneration of beta-cells in the adult pancreas. Diabetes $54,2586-2595$

Horb, M.E., Shen, C.N., Tosh, D., Slack, J.M., 2003. Experimental conversion of liver to pancreas. Curr. Biol. 13, 105-115.

Inada, A., Nienaber, C., Katsuta, H., Fujitani, Y., Levine, J., Morita, R., Sharma, A., Bonner-Weir, S., 2008. Carbonic anhydrase II-positive pancreatic cells are progenitors for both endocrine and exocrine pancreas after birth. Proc. Natl. Acad. Sci. U.S.A..

Jenny, M., Uhl, C., Roche, C., Duluc, I., Guillermin, V., Guillemot, F., Jensen, J., Kedinger, M., Gradwohl, G., 2002. Neurogenin3 is differentially required for endocrine cell fate specification in the intestinal and gastric epithelium. EMBO J. 21, 6338-6347.

Johansson, K.A., Dursun, U., Jordan, N., Gu, G., Beermann, F., Gradwohl, G., Grapin-Botton, A., 2007. Temporal control of neurogenin3 activity in pancreas progenitors reveals competence windows for the generation of different endocrine cell types. Dev. Cell 12, 457-465.

Jørgensen, M.C., Ahnfelt-Rønne, J., Hald, J., Madsen, O.D., Serup, P., HecksherSørensen, J., 2007. An illustrated review of early pancreas development in the mouse. Endocr. Rev. 28 (6), 685-705.

Kaneto, H., Nakatani, Y., Miyatsuka, T., Matsuoka, T.A., Matsuhisa, M., Hori, M., Yamasaki, Y., 2005. PDX1/VP16 fusion protein, together with NeuroD or Ngn3, markedly induces insulin gene transcription and ameliorates glucose tolerance. Diabetes 54, 1009-1022.
Krapp, A., Knofler, M., Frutiger, S., Hughes, G.J., Hagenbuchle, O., Wellauer, P.K., 1996. The p48 DNA-binding subunit of transcription factor PTF1 is a new exocrine pancreas-specific basic helix-loop-helix protein. EMBO J. 15, 43174329.

Krapp, A., Knofler, M., Ledermann, B., Burki, K., Berney, C., Zoerkler, N., Hagenbuchle, O., Wellauer, P.K., 1998. The bHLH protein PTF1-p48 is essential for the formation of the exocrine and the correct spatial organization of the endocrine pancreas. Genes Dev. 12, 3752-3763.

Lingohr, M.K., Buettner, R., Rhodes, C.J., 2002. Pancreatic beta-cell growth and survival-a role in obesity-linked type 2 diabetes? Trends Mol. Med. 8, 375-384.

Lynn, F.C., Smith, S.B., Wilson, M.E., Yang, K.Y., Nekrep, N., German, M.S., 2007. Sox 9 coordinates a transcriptional network in pancreatic progenitor cells. Proc. Natl. Acad. Sci. U.S.A. 104 (25), 10500-10505.

Matsuoka, T.A., Artner, I., Henderson, E., Means, A., Sander, M., Stein, R., 2004. The MafA transcription factor appears to be responsible for tissue-specific expression of insulin. Proc. Natl. Acad. Sci. U.S.A. 101, 2930-2933.

Matsuoka, T.A., Kaneto, H., Stein, R., Miyatsuka, T., Kawamori, D., Henderson, E., Kojima, I., Matsuhisa, M., Hori, M., Yamasaki, Y., 2007. MafA regulates expression of genes important to islet beta-cell function. Mol. Endocrinol. 21, 2764-2774.

Matsuoka, T.A., Zhao, L., Artner, I., Jarrett, H.W., Friedman, D., Means, A., Stein, R. 2003. Members of the large Maf transcription family regulate insulin gene transcription in islet beta cells. Mol. Cell. Biol. 23, 6049-6062.

Mellitzer, G., Bonne, S., Luco, R.F., Van De Casteele, M., Lenne-Samuel, N., Collombat, P., Mansouri, A., Lee, J., Lan, M., Pipeleers, D., Nielsen, F.C., Ferrer, J., Gradwohl, G., Heimberg, H., 2006. IA1 is NGN3-dependent and essential for differentiation of the endocrine pancreas. EMBO J. 25, 1344-1352.

Miyatsuka, T., Kaneto, H., Shiraiwa, T., Matsuoka, T.A., Yamamoto, K., Kato, K. Nakamura, Y., Akira, S., Takeda, K., Kajimoto, Y., Yamasaki, Y., Sandgren, E.P., Kawaguchi, Y., Wright, C.V., Fujitani, Y., 2006. Persistent expression of PDX1 in the pancreas causes acinar-to-ductal metaplasia through Stat 3 activation. Genes Dev. 20, 1435-1440.

Nelson, S.B., Schaffer, A.E., Sander, M., 2007. The transcription factors Nkx6.1 and Nkx6.2 possess equivalent activities in promoting beta-cell fate specification in Pdx1+ pancreatic progenitor cells. Development 134, 2491-2500.

Nir, T., Dor, Y., 2005. How to make pancreatic beta cells-prospects for cell therapy in diabetes. Curr. Opin. Biotechnol. 16, 524-529.

Nir, T., Melton, D.A., Dor, Y., 2007. Recovery from diabetes in mice by beta cell regeneration. J. Clin. Invest. 117, 2553-2561.

Offield, M.F. Jetton, T.L, Labosky, P.A., Ray, M. Stein, R.W. Magnuson, M.A, Hogan, B.L., Wright, C.V., 1996. PDX1 is required for pancreatic outgrowth and differentiation of the rostral duodenum. Development 122, 983-995.

Ohlsson, H., Karlsson, K., Edlund, T., 1993. IPF1, a homeodomain-containing transactivator of the insulin gene. EMBO J. 12, 4251-4259.

Oliver-Krasinski, J.M., Stoffers, D.A., 2008. On the origin of the beta cell. Genes Dev. 22, 1998-2021.

Oster, A., Jensen, J., Edlund, H., Larsson, L.I., 1998. Homeobox gene product Nkx 6.1 immunoreactivity in nuclei of endocrine cells of rat and mouse stomach. J. Histochem. Cytochem. 46, 717-721.

Pedersen, J.K., Nelson, S.B., Jorgensen, M.C., Henseleit, K.D., Fujitani, Y., Wright, C.V. Sander, M., Serup, P., 2005. Endodermal expression of Nkx6 genes depends differentially on Pdx1. Dev. Biol. 288, 487-501.

Pictet, R.L., Clark, W.R., Williams, R.H., Rutter, W.J., 1972. An ultrastructural analysis of the developing embryonic pancreas. Dev. Biol. 29, 436-467.

Prado, C.L., Pugh-Bernard, A.E., Elghazi, L., Sosa-Pineda, B., Sussel, L., 2004. Ghrelin cells replace insulin-producing beta cells in two mouse models of pancreas development. Proc. Natl. Acad. Sci. U.S.A. 101, 2924-2929.

Roncoroni, L., Violi, V., Montanari, M., Muri, M., 1983. Effect of somatostatin on exocrine pancreas evaluated on a total external pancreatic fistula of neoplastic origin. Am. J. Gastroenterol. 78, 425-428.

Sander, M., Neubüser, A., Kalamaras, J., Ee, H.C., Martin, G.R., German, M.S., 1997. Genetic analysis reveals that PAX6 is required for normal transcription of pancreatic hormone genes and islet development. Genes Dev. 11 (13), 1662 1673.

Sander, M., Sussel, L., Conners, J., Scheel, D., Kalamaras, J., Dela Cruz, F., Schwitzgebel, V., Hayes-Jordan, A., German, M., 2000. Homeobox gene Nkx6.1 lies downstream of Nkx2.2 in the major pathway of beta-cell formation in the pancreas. Development $127,5533-5540$.

Schwitzgebel, V.M., Scheel, D.W., Conners, J.R., Kalamaras, J., Lee, J.E., Anderson, D.J., Sussel, L., Johnson, J.D., German, M.S., 2000. Expression of neurogenin3 reveals an islet cell precursor population in the pancreas. Development 127, 35333542.

Seymour, P.A., Freude, K.K., Tran, M.N., Mayes, E.E., Jensen, J., Kist, R., Scherer, G., Sander, M., 2007. SOX9 is required for maintenance of the pancreatic progenito cell pool. Proc. Natl. Acad. Sci. U.S.A. 104 (6), 1865-1870.

Seymour, P.A., Freude, K.K., Dubois, C.L., Shih, H.P., Patel, N.A., Sander, M., 2008. A dosage-dependent requirement for Sox9 in pancreatic endocrine cell formation. Dev. Biol. 323 (1), 19-30.

Shternhall-Ron, K., Quintana, F.J., Perl, S., Meivar-Levy, I., Barshack, I., Cohen, I.R. Ferber, S., 2007. Ectopic PDX1 expression in liver ameliorates type 1 diabetes. J. Autoimmun. 28, 134-142.

Sosa-Pineda, B., Chowdhury, K. Torres, M., Oliver, G, Gruss, P. 1997. The Pax4 gene is essential for differentiation of insulin-producing beta cells in the mammalian pancreas. Nature 386, 399-402.

St-Onge, L., Sosa-Pineda, B., Chowdhury, K., Mansouri, A., Gruss, P., 1997. Pax6 is required for differentiation of glucagon-producing alpha-cells in mouse pancreas. Nature 387, 406-409. 
18

S. Kordowich et al. / Molecular and Cellular Endocrinology 315 (2010) 11-18

Stoffers, D.A., Heller, R.S., Miller, C.P., Habener, J.F., 1999. Developmental expression of the homeodomain protein Idx-1 in mice transgenic for an Idx-1 promoter/Lacz transcriptional reporter. Endocrinology 140, 5374-5381.

Sussel, L., Kalamaras, J., Hartigan-O'connor, D.J., Meneses, J.J., Pedersen, R.A., Rubenstein, J.L., German, M.S., 1998. Mice lacking the homeodomain transcription factor Nkx2.2 have diabetes due to arrested differentiation of pancreatic beta cells. Development 125, 2213-2221.

Takahashi, K., Yamanaka, S., 2006. Induction of pluripotent stem cells from mouse embryonic and adult fibroblast cultures by defined factors. Cell 126, 663-676.

Taniguchi, H., Yamato, E., Tashiro, F., Ikegami, H., Ogihara, T., Miyazaki, J., 2003. Betacell neogenesis induced by adenovirus-mediated gene delivery of transcription factor Pdx1 into mouse pancreas. Gene Ther. 10, 15-23.

Teitelman, G., Alpert, S., Polak, J.M., Martinez, A., Hanahan, D., 1993. Precursor cells of mouse endocrine pancreas coexpress insulin, glucagon and the neuronal proteins tyrosine hydroxylase and neuropeptide $\mathrm{Y}$, but not pancreatic polypeptide. Development 118, 1031-1039.

Teta, M., Rankin, M.M., Long, S.Y., Stein, G.M., Kushner, J.A., 2007. Growth and regeneration of adult beta cells does not involve specialized progenitors. Dev. Cell 12, 817-826.

Tosh, D., Slack, J.M., 2002. How cells change their phenotype. Nat. Rev. Mol. Cell Biol. 3, 187-194.

Upchurch, B.H., Aponte, G.W., Leiter, A.B., 1994. Expression of peptide YY in all four islet cell types in the developing mouse pancreas suggests a common peptide YY-producing progenitor. Development 120, 245-252.

Villasenor, A., Chong, D.C., Cleaver, O., 2008. Biphasic Ngn3 expression in the developing pancreas. Dev. Dyn. 237, 3270-3279.

Wang, S., Jensen, J.N., Seymour, P.A., Hsu, W., Dor, Y., Sander, M., Magnuson, M.A., Serup, P., Gu, G., 2009. Sustained Neurog3 expression in hormone-expressing islet cells is required for endocrine maturation and function. Proc. Natl. Acad. Sci. U.S.A. 106 (24), 9715-9720.
Wang, R.N., Kloppel, G., Bouwens, L., 1995. Duct- to islet-cell differentiation and islet growth in the pancreas of duct-ligated adult rats. Diabetologia 38, 1405-1411.

Wiebe, P.O., Kormish, J.D., Roper, V.T., Fujitani, Y., Alston, N.I., Zaret, K.S., Wright C.V., Stein, R.W., Gannon, M., 2007. Ptf1a binds to and activates area III, a highly conserved region of the Pdx1 promoter that mediates early pancreas-wide Pdx1 expression. Mol. Cell. Biol. 27, 4093-4104.

Wierup, N., Svensson, H., Mulder, H., Sundler, F., 2002. The ghrelin cell: a novel developmentally regulated islet cell in the human pancreas. Regul. Pept. 107, 63-69.

Xu, X., D’hoker, J., Stange, G., Bonne, S., De Leu, N., Xiao, X., Van De Casteele, M., Mellitzer, G., Ling, Z., Pipeleers, D., Bouwens, L., Scharfmann, R., Gradwohl, G., Heimberg, H., 2008. Beta cells can be generated from endogenous progenitors in injured adult mouse pancreas. Cell 132, 197-207.

Yechoor, V., Liu, V., Espiritu, C., Paul, A., Oka, K., Kojima, H., Chan, L., 2009. Neurogenin3 is sufficient for transdetermination of hepatic progenitor cells into neo-islets in vivo but not transdifferentiation of hepatocytes. Dev. Cell 16 (3), 358-373.

Zhang, C., Moriguchi, T., Kajihara, M., Esaki, R., Harada, A., Shimohata, H., Oishi, H., Hamada, M., Morito, N., Hasegawa, K., Kudo, T., Engel, J.D., Yamamoto, M., Takahashi, S., 2005. MafA is a key regulator of glucose-stimulated insulin secretion. Mol. Cell. Biol. 25, 4969-4976.

Zhao, L., Guo, M., Matsuoka, T.A., Hagman, D.K., Parazzoli, S.D., Poitout, V., Stein, R., 2005. The islet beta cell-enriched MafA activator is a key regulator of insulin gene transcription. J. Biol. Chem. 280, 11887-11894.

Zhou, Q., Brown, J., Kanarek, A., Rajagopal, J., Melton, D.A., 2008. In vivo reprogramming of adult pancreatic exocrine cells to beta-cells. Nature 455, 627-632.

Zhou, Q., Law, A.C., Rajagopal, J., Anderson, W.J., Gray, P.A., Melton, D.A., 2007. A multipotent progenitor domain guides pancreatic organogenesis. Dev. Cell 13, 103-114. 